\title{
ARTERIAL AND CAPILLARY BLOOD OXYGEN TENSIONS
}

\author{
Major A. J. SPICER, M.B., B.S., M.R.C.P., D.C.H., D.T.M.\&H., R.A.M.C. \\ British Military Hospital, Iserlohn
}

SUMMARY: 'Samples of arterial and capillary blood were obtained simultaneously and the oxygen tension of each was measured. The correlation between arterial blood and capillary blood oxygen tension was reasonably good except in patients with disturbed circulation. Because of these discrepancies and the simplicity of arterial blood sampling it is recommended that measurement of arterial blood oxygen tension is the method of choice.

The decline of oxygen tension of arterial blood contained in plastic syringes at room temperature was assessed. The results indicated that for routine clinical practice blood may be stored in plastic syringes at room temperature for periods up to one hour after sampling.

A method of arterial puncture is described.

\section{Introduction}

It is becoming increasingly important to estimate blood oxygen tensions. Measurement of the $\mathrm{P}_{\mathrm{O} 2}$ and $\mathrm{P}_{\mathrm{CO} 2}$ is the only certain method of diagnosing the presence and severity of respiratory failure. The management of respiratory failure depends on serial estimations of the $\mathrm{P}_{\mathrm{O} 2}$ and $\mathrm{P}_{\mathrm{CO} 2}$ in order to steer a course between hypoxia and hypercapnia. In the respiratory distress syndrome of the newborn, analysis of the arterial oxygen tension enables the arterial $P_{\mathrm{O} 2}$ to be maintained between 70 and $150 \mathrm{mmHg}$ and the effects of hypoxia or excessive oxygen administration avoided. It is essential to monitor patients receiving intermittent positive pressure respiration by regular blood gas analysis. Measurement of the $\mathrm{P}_{\mathrm{O} 2}$ and $\mathrm{P}_{\mathrm{CO} 2}$ is an important aid to the diagnosis of major pulmonary embolism.

This investigation was performed under routine conditions in two military hospitals in order to study (a) the correlation in oxygen tension between arterial and capillary blood; $(b)$ the rate of decline of oxygen tension of arterial blood contained in plastic syringes after sampling. The decline of oxygen tension was only assessed up to two hours, as to be of practical value a result must be available within this time. Plastic syringes were chosen rather than glass syringes because the former are in everyday use. The decline of $\mathrm{P}_{\mathrm{O} 2}$ was measured at $18^{\circ} \mathrm{C}$ because this is the normal laboratory room temperature in Western Europe. At the same time it was intended that the author should gain experience of arterial puncture and the technicians should become accustomed to measuring blood $\mathrm{P}_{\mathrm{O} 2}$.

\section{Methods}

Oxygen tension was measured with a Radiometer E 5406 oxygen electrode fitted with a Radiometer D 604 polypropylene membrane. All medsurements were made at $37^{\circ} \mathrm{C}$. The span of the measuring instrument was set at $0-200 \mathrm{mmHg}$, and the electrode calibrated at an oxygen tension of $0 \mathrm{mmHg}$ by using a freshly made saturated solution of sodium sulphite in $0.01 \mathrm{M}$ borax solution. The linearity of response was ascertained using air equilibrated thermostat water which contains oxygen at a partial pressure of 
about $150 \mathrm{mmHg}$. As air contains 20.9 per cent of oxygen, and the saturated vapour pressure of water at $37^{\circ} \mathrm{C}$ is $47 \mathrm{mmHg}$, the actual $\mathrm{P}_{\mathrm{O} 2}$ was calculated as follows-

$$
\left.P_{\mathrm{O} 2}=\frac{20.9}{100} \times \text { (barometric pressure }-47\right) \mathrm{mmHg} \text {. }
$$

The electrode was recalibrated between each estimation in order to correct drift. Arterial blood samples were mixed immediately before each estimation by rolling the syringe between the palms.

Arterial and capillary blood sampling were performed simultaneously on patients in a steady respiratory state. It was done on patients for whom it was necessary for diagnostic purposes or for monitoring treatment, and on volunteers under general anaesthesia who were having elective surgical operations. The day before operation the procedure and the reason for performing it was carefully explained and permission requested. Although these patients understood that the investigation was of no direct benefit to them, none declined. Various concentrations of oxygen ranging from 21 to 40 per cent, were administered whilst the patients were breathing spontaneously under anaesthesia.

Capillary blood samples were obtained from the ear lobe which was massaged between index finger and thumb for three minutes prior to sampling. A small cruciate skin puncture was made by two insertions of a "Steriseal" disposable lancet. A heparinised capillary tube was completely filled with blood by placing one end in contact with the puncture so that blood flowed directly into the tube without contact with air. A small steel rod was placed in the tube, the ends sealed with Radiometer sealing wax, and the blood mixed with heparin by moving the steel rod up and down with the aid of a magnet. Two capillary tube samples were used for each $\mathrm{P}_{\mathrm{O} 2}$ estimation.

Arterial blood was obtained from the radial artery. A $10 \mathrm{ml}$ disposable plastic syringe (Johnson and Johnson Ltd.) and a $25 \mathrm{~g} \times 16 \mathrm{~mm}$ intradermal needle were used. Clotting was prevented by drawing a small volume of heparin, 25000 units per $\mathrm{ml}$, into the syringe and ejecting it through the needle to be used for arterial puncture. Sufficient heparin remained in the needle and nozzle of the syringe to prevent clotting of $10 \mathrm{ml}$ of blood. The volume of this residual heparin was $0.05 \mathrm{ml}$ and the dilution effect on the $\mathrm{P}_{\mathrm{O} 2}$ value can be ignored for practical purposes. With the wrist held in dorsiflexion the radial artery was located by palpation. The skin was pierced at right angles and the artery transfixed against the underlying radius. Gentle negative pressure was applied with the syringe and the needle withdrawn until the lumen of the artery was entered and blood aspirated. Minimal negative pressure was then exerted with the plunger to avoid pulling gas out of solution, which would result in a low $\mathbf{P}_{\mathrm{O} 2}$. After aspiration the needle was sealed by inserting it into a rubber cork and the syringe rolled between the palms to assist diffusion of the heparin. The discomfort of this procedure is slight and local analgesia was not required.

\section{Results}

Figure 1 shows the correlation between capillary blood oxygen tension and arterial blood oxygen tension. It can be seen that the correlation was reasonably good. The capillary $P_{\mathrm{O} 2}$ had a mean value of $101 \mathrm{mmHg}$ and the arterial $\mathbf{P}_{\mathrm{O} 2}$ had a mean value of $108 \mathrm{mmHg}$. The difference was approximately the same throughout the tested range 
of oxygen tension of 60 to $200 \mathrm{mmHg}$. However, there were three discrepancies in seriously ill patients. The capillary $P_{\mathrm{O} 2}$ exceeded the arterial $\mathrm{P}_{\mathrm{O} 2}$ by $20 \mathrm{mmHg}$ in a patient with acute on chronic respiratory failure (Fig. 1 (a)). The arterial $\mathrm{P}_{\mathrm{O}_{2}}$ exceeded the capillary $P_{\mathrm{O} 2}$ by $22 \mathrm{mmHg}$ in a patient with cardiogenic shock (b), and by $20 \mathrm{mmHg}$ in a curarised patient receiving intermittent positive pressure respiration for intractable status apilepticus (c).

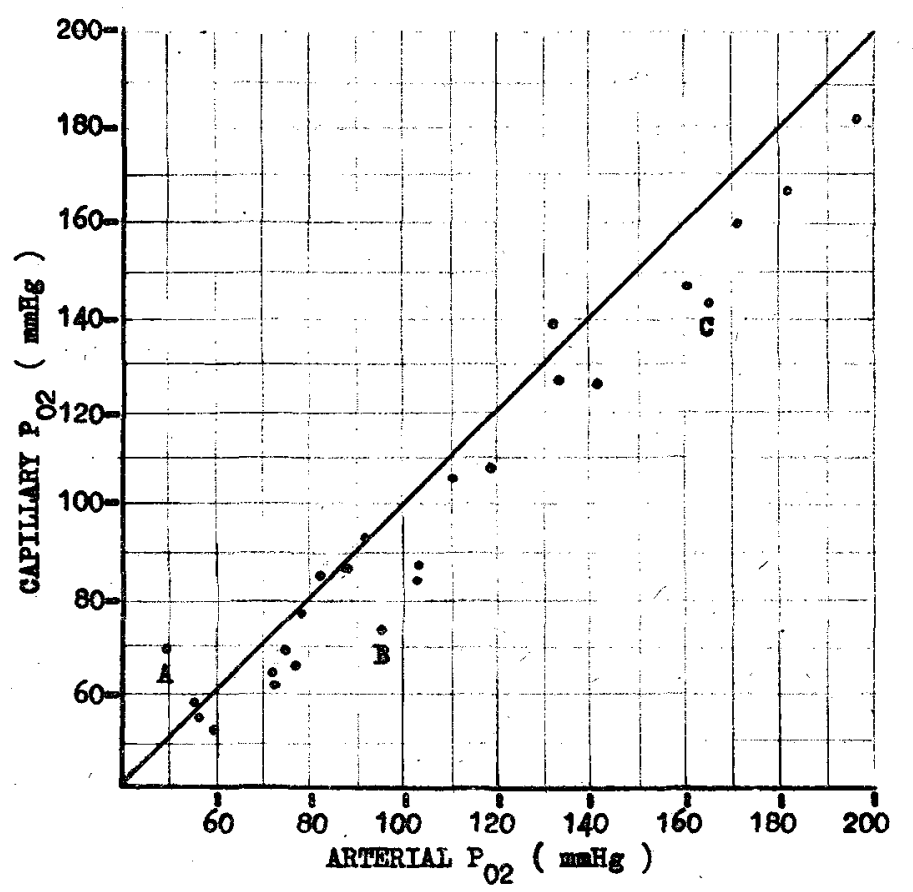

Fig. 1. $P_{02}$ of capillary blood plotted against $P_{02}$ of arterial blood. (a) From a patient in respiratory failure. (b) From a patient in cardiogenic shock. (c) From a patient receiving intermittent positive pressure respiration. The diagonal is the $45^{\circ}$ reference line.

Table 1 presents the results obtained by measuring the $\mathrm{P}_{\mathrm{O} 2}$ at half hourly intervals of blood stored in plastic syringes at about $18^{\circ} \mathrm{C}$. The results are expressed as a percentage fall, corrected to the nearest whole number, of the original partial pressure. After half an hour there was a mean fall of 2 per cent with a range of 0 to 5 per cent. There was a linear fall of about 2 per cent for each subsequent half hour. After two hours there was a mean fall of 9 per cent with a range of 4 to 16 per cent.

\section{Discussion}

Various authors (Laughlin, McDonald and Bedell 1964, Langlands and Wallace 1965, Spock, Hinton and Albertson 1966, MacIntyre and Norman 1968) have recorded a satisfactory correlation between capillary blood and arterial blood $\mathrm{P}_{\mathrm{O} 2}$ levels, provided that the peripheral circulation is normal. Most authors agree that capillary blood samples give discrepant results when there is disturbance of the peripheral circulation, such as occurs in shock, pain, cold and anaesthesia. However, it is often in such patients that knowledge of the $\mathrm{P}_{\mathrm{O} 2}$ is most important and inaccurate results may lead to errors in treatment. The discrepant results in this study were from three patients for whom 
Table I

Fall of $\mathrm{P}_{02}$ in arterial blood samples stores in plastic syringes at $18^{\circ} \mathrm{C}$

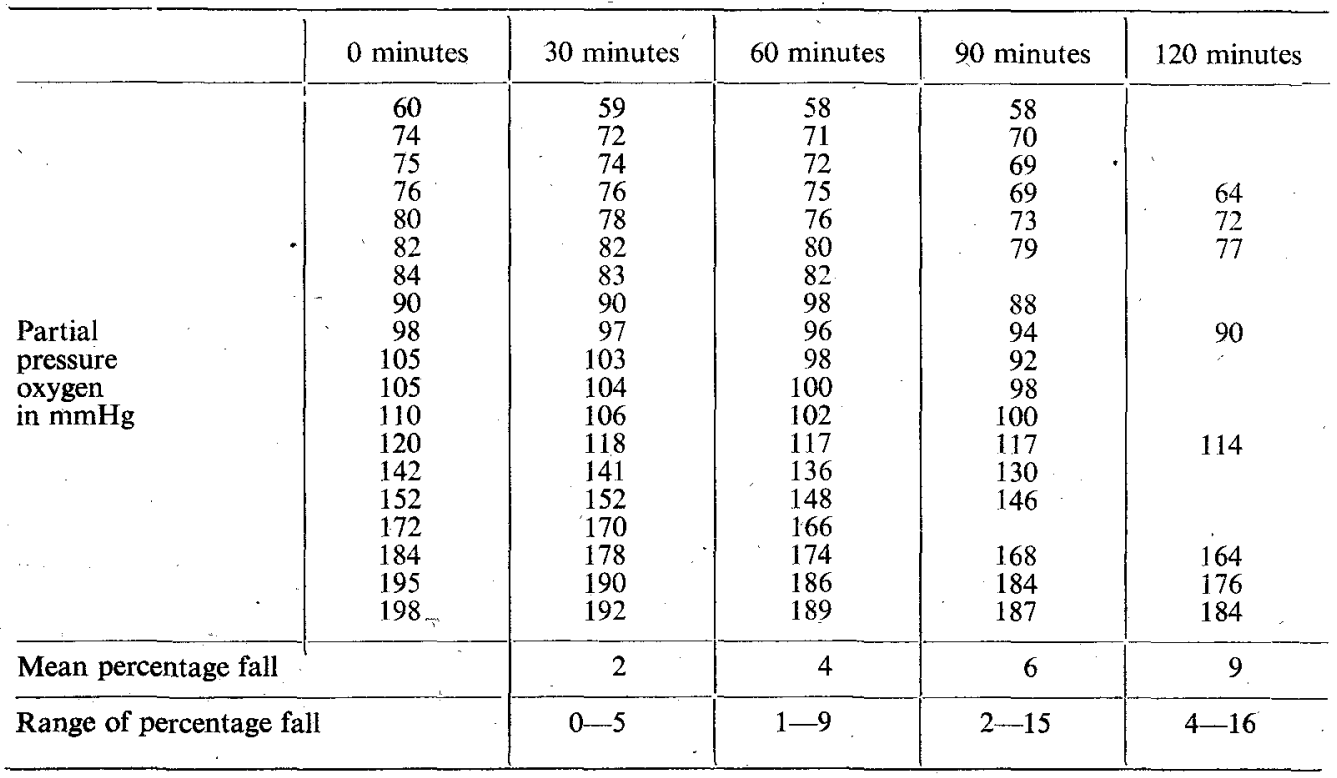

knowledge of the $\mathrm{P}_{\mathrm{O} 2}$ was important for diagnosis and management, but who had disturbance of the peripheral circulation.

The procedure of arterial puncture, as described in this paper, is simple and safe and there seems little reason to rely on capillary blood sampling with its inherent errors. Patients find the discomfort of radial artery puncture with a $25 \mathrm{~g} 16 \mathrm{~mm}$ needle less than that of massage and puncture of the ear lobe. The author has performed over forty arterial punctures by this method and there have been no failures and no problems.

There are very few published accounts on the percentage fall of $\mathrm{P}_{\mathrm{O} 2}$ over the range of $50-200 \mathrm{mmHg}$ of blood contained in plastic syringes at room temperature. This is surprising, as these are the conditions which pertain to normal practice. Most of these accounts record the fall of $\mathrm{P}_{\mathrm{O} 2}$ in millimetres of $\mathrm{Hg}$. Such reports have a limited value as they only indicate the expected fall for a particular initial $\mathrm{P}_{\mathrm{O} 2}$ level. Scott, Horton and Mapleson (1971) record a fall of 5.8 per cent of an initial $\mathrm{P}_{\mathrm{O} 2}$ of $100 \mathrm{mmHg}$ in blood stored in a plastic syringe for one hour at $22.5^{\circ} \mathrm{C}$. MacIntyre and Norman (1968) record a fall of 14 per cent of an initial $\mathrm{P}_{\mathrm{O} 2}$ of $143 \mathrm{mmHg}$ in blood stores in a plastic syringe for one hour at $21^{\circ} \mathrm{C}$. A search of the literature has failed to reveal a study in depth on the fall on $\mathrm{P}_{\mathrm{O} 2}$ of arterial blood samples under the conditions described in this paper. In this study on 19 arterial blood samples the mean fall of $\mathrm{P}_{\mathrm{O} 2}$ was 4 per cent with a range of 1 to 9 per cent at one hour. It is unlikely that such a change would influence clinical . management and the results indicate that for routine clinical practice blood may be stored in plastic syringes at room temperature for periods up to one hour.

\section{REFERENCES}

LANGlands, J. H. M. and Wallace, W. F. M. (1965). Lancet ii, 315.

Laughlin, D. E. MCDonald, J. S. and Bedell, G. N. (1964). J. Lab. clin. Med. 64, 330.

MacInTyre, J. and Norman, J. N. (1968). Brit. med. J. ii, 640.

Scott, P. V., Horton, J. N. and Mapleson, W. W. (1971). Brit. med. J. 2, 512.

Spock, A., Hinton, M. L. and Albertson, T. H. (1966). J. Practice 68, 987. 